
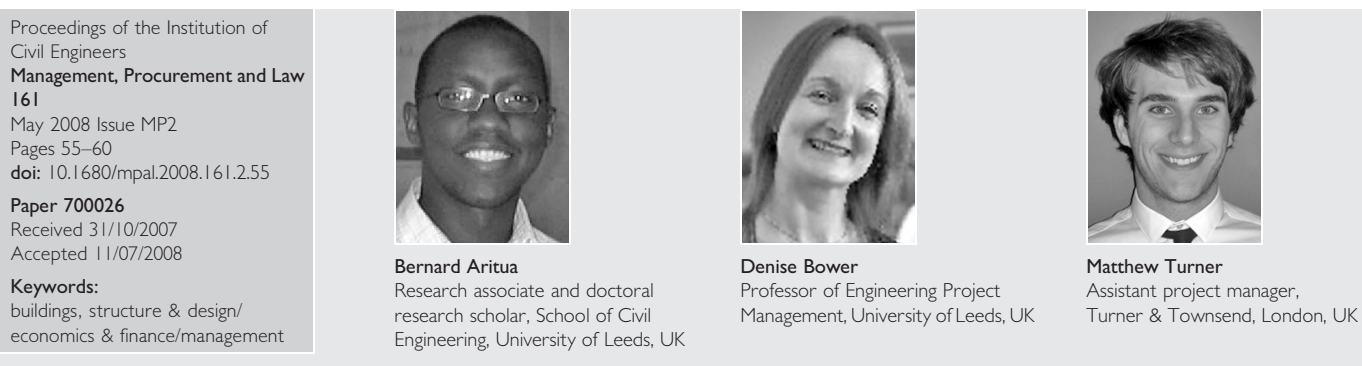

\title{
Managing the delivery of iconic football stadiums in England
}

\section{B. Aritua MSc, GMICE, MAPM, D. Bower BEng, PhD, MASCE and M. Turner MSc}

The English football premier league has become the most popular sports league in the world; with ardent fans and audiences all over the world. The potential business opportunities that this growth holds have therefore attracted investors who are keen to buy shares in the clubs and sign up the best footballers that money can buy. Underpinning the growth in all of the premier league clubs is a desire to make a distinct statement of identity as part of a competitive strategy. One way to achieve this is through the design and construction of iconic football stadiums. This paper explores the specific project management challenges associated with delivery of iconic football stadiums in England and draws lessons for the management of similar iconic infrastructure projects. A study of project management best practice and some case studies shows that key issues which are common to these projects are centred on design management; choice of procurement route; client management; and stakeholder expectation management. These issues are not necessarily unique to the project management of iconic football stadiums but are amplified by the context of these projects. The emphasis on iconic status in a competitive market also means that stadium projects should be conceived and delivered in the context of other strategic projects which should be clearly understood by the project management team.

\section{INTRODUCTION}

The record of English football in the last 20 years has come to represent a remarkable turnaround. Today the English premiership remains the largest and most profitable league in world football, with recorded revenues well ahead of all of the other top divisions in football. Among the top 20 richest football clubs in a recent study by the Deloitte organisation, ${ }^{1}$ eight are from the English premier league. Over and above the domestic attraction of premiership clubs is the revenues from television broadcasts, club merchandise, advertising, and sponsorship deals, which have made the clubs potentially lucrative business opportunities for investors from far and wide.

The example of Manchester United, English football's most successful team in the last decade, epitomises this trend. From being run by an enterprising butcher through much of the 1960s and 1970s it was taken over by the US businessman Malcolm Glazer in 2005. In addition to Manchester United, other premier league clubs currently owned by foreign investors include: Chelsea, Liverpool, West Ham, Aston Villa, Manchester City and Portsmouth. There are also persistent rumours of possible purchase of others such as Arsenal, Birmingham City and Blackburn Rovers by investors. A key factor impacting on the business objectives is the ability to increase the capacity of the stadiums and make a statement of distinct identity. Some clubs choose to achieve these two objectives through design and construction of iconic stadiums capable of providing sports and leisure facilities.

One option available to most clubs is to invest in their current stadium in a bid to increase match-day revenues and remodel the design features in order to achieve iconic status through the stadium. Manchester United has taken this investment option (Fig. 1). Other clubs such as Newcastle United and Aston Villa have also followed suit.

Due to the constraints of existing facilities and location of their current grounds, a number of clubs have been forced to consider the complete development of a new stadium. Examples of new stadiums constructed include: Arsenal's Emirates stadium (Fig. 2), Bolton's Reebok stadium and the City of Manchester stadium. Other clubs such as Liverpool, Everton and Portsmouth are involved in new stadium projects albeit at differing stages. The idea of a new stadium is highly appealing to clubs as it provides an opportunity to start with a clean slate and deliver a modern iconic centrepiece as well as a financial stepping stone for the club's future.

The choice for most clubs is therefore a simple one: either redevelop or relocate. For some football clubs the redevelopment option may not be viable due to space constraints around the existing facilities. Current trends show that over the next decade numerous other football clubs will look to modernise their stadiums. This includes clubs at different positions on the premiership table, and those aspiring for promotion to the Premier League.

In the context of the strategic business approach to managing clubs, the design and construction of new iconic stadiums should therefore be undertaken as part of an overall strategic change project. The next section examines the strategic need for iconic football stadiums. Subsequently, the project management challenges associated with delivery of iconic stadiums will be explored. The discussions are based on an extensive literature search of project management best practice and a number of 


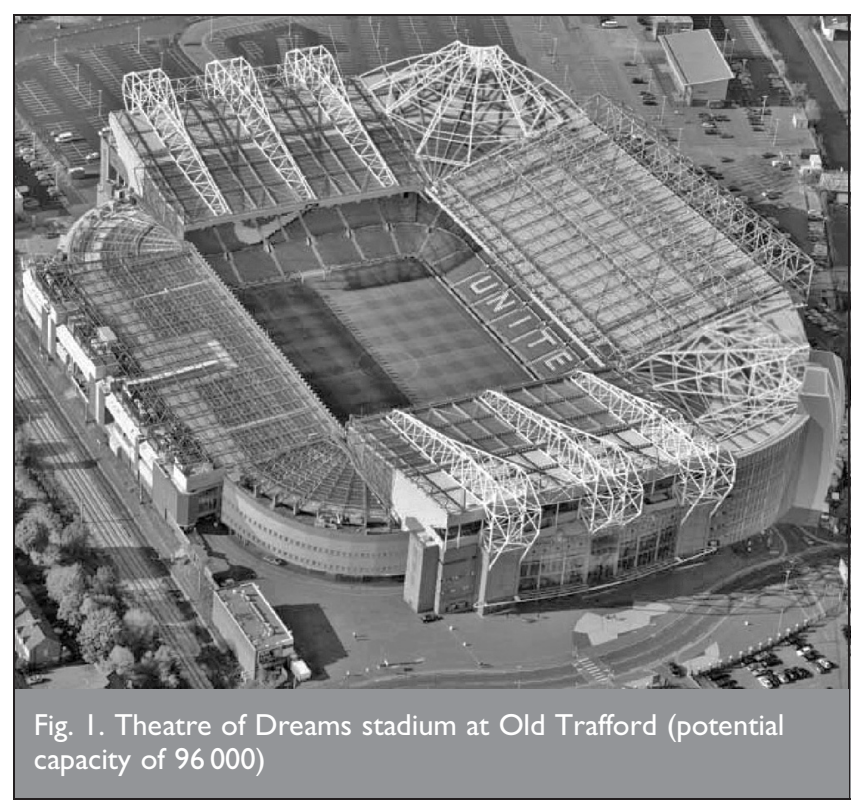

case studies. The findings were validated through a series of semi-structured interviews with clubs and organisations involved in project management of football stadiums.

\section{THE STRATEGIC NEED FOR ICONIC FOOTBALL STADIUMS}

Iconic structures stand apart from the functional and mundane. They are often expected to be architecturally magnificent and breathtakingly beautiful. It must however be admitted that whether something is iconic or not is much more than just an appreciation of its architecture; after all the aesthetic value of a building can be a very subjective judgement. However, there seems to be wide range consensus that iconic structures grasp the attention of local, national and even worldwide audiences and build a sense of brand identity. This notion is supported by Sklair, ${ }^{2}$ who notes that an iconic building generally has two defining characteristics. First, it clearly carries the idea of fame, and second, iconicity also has a symbolic/aesthetic value. In his view an architectural icon is imbued with a special meaning that is symbolic of a culture and/or a time. Betsky ${ }^{3}$ argues that icons carry a sense of monumentality and enigmatic character that exudes hypnotic quality.

From the Great Pyramids of Giza, to the Colosseum in Rome, the Eiffel Tower in Paris, the Sydney Opera House, and Big Ben in London, the strategic and financial potential of iconic structures is obvious. The example of Manchester United also proves this point. During the 2005-2006 season Manchester United received a total of $£ 71 \cdot 3$ million from match-day sources, which accounted for $43 \%$ of their overall revenue. This figure increased again during the 2006-2007 season as the Old Trafford capacity increased from 68000 to 76000 . With emphasis on the iconic status of the Theatre of Dreams, other activities such as guided tours round the stadium and the museum, use of conference/events facilities and sale of merchandise have also increased in England and abroad.

The need for commercially viable clubs to incorporate iconic status football stadiums amid a competitive market is further justified in the light of Porter's five-forces of competitive strategy ${ }^{4}$ shown in Fig. 3.

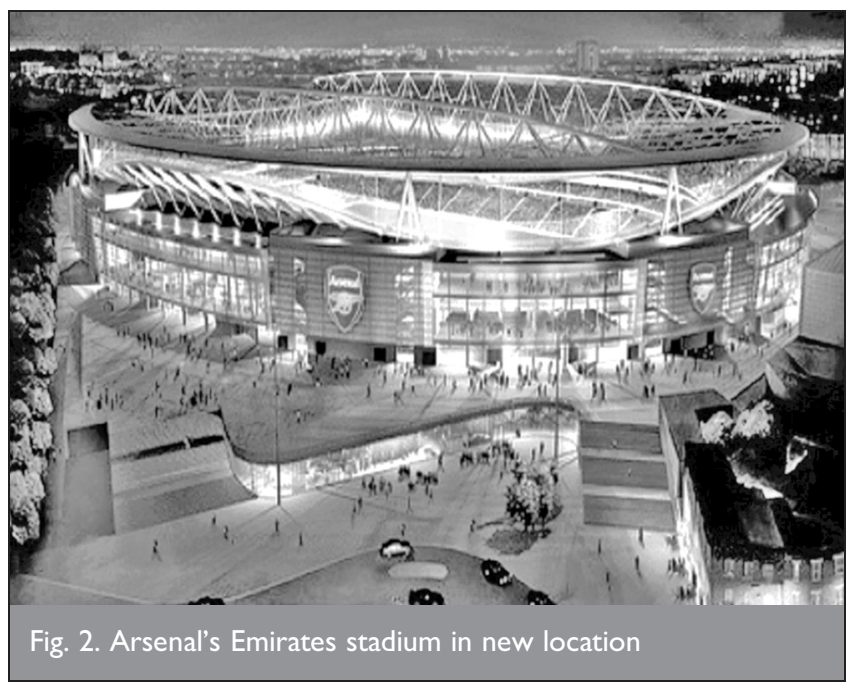

Porter's five-forces model provides a framework for examining the competitive environment of an organisation. According to this model, the most competitive markets will be those in which entry is likely, substitutes threaten, or buyers/suppliers exercise control. With a total of 20 clubs competing to stay in the league and the threat of relegation and replacement by clubs from lower divisions, much effort is dedicated by most clubs to establish some sort of identity to attract additional revenues that would bolster the chances of acquiring top rate players and sustaining their ever-increasing wages. The bargaining power of suppliers and buyers needed to support continuous growth is a big issue for premiership clubs in the face of powerful and concentrated brands for sponsorship, advertising and TV coverage. As seen in the case of the traditionally top four clubs (Manchester United, Arsenal, Liverpool and Chelsea) this has a direct link to revenues. As such, these clubs have taken steps to reposition themselves and shift the balance, and each one of them either has a new stadium or is taking steps towards acquiring one. Other clubs that have recently acquired new facilities have also had better performance both on and off the pitch (for example, Manchester City and Aston Villa). Competitive advantage is generally also obtained by differentiation to reduce the likelihood of customers shifting allegiance.

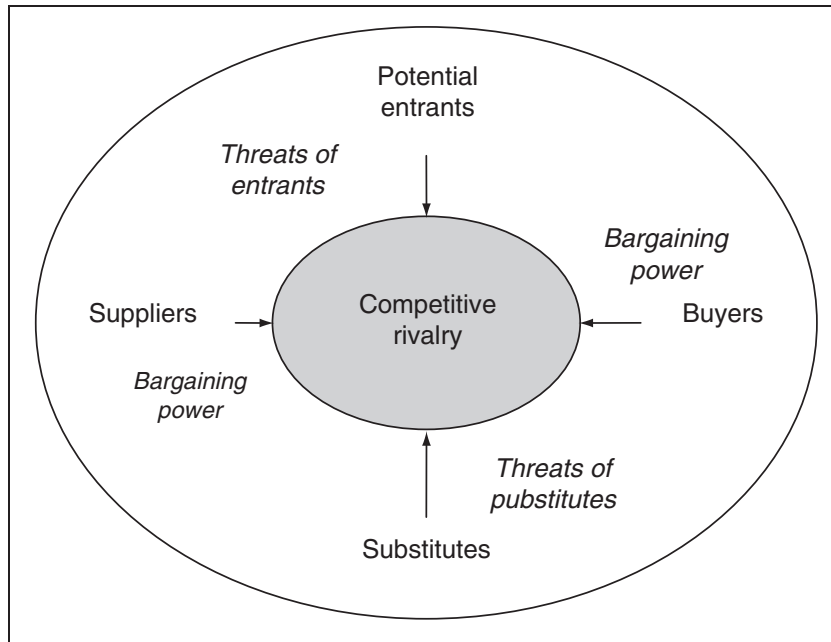

Fig. 3. Five-forces of competitive strategy: adapted from Porter ${ }^{4}$ 


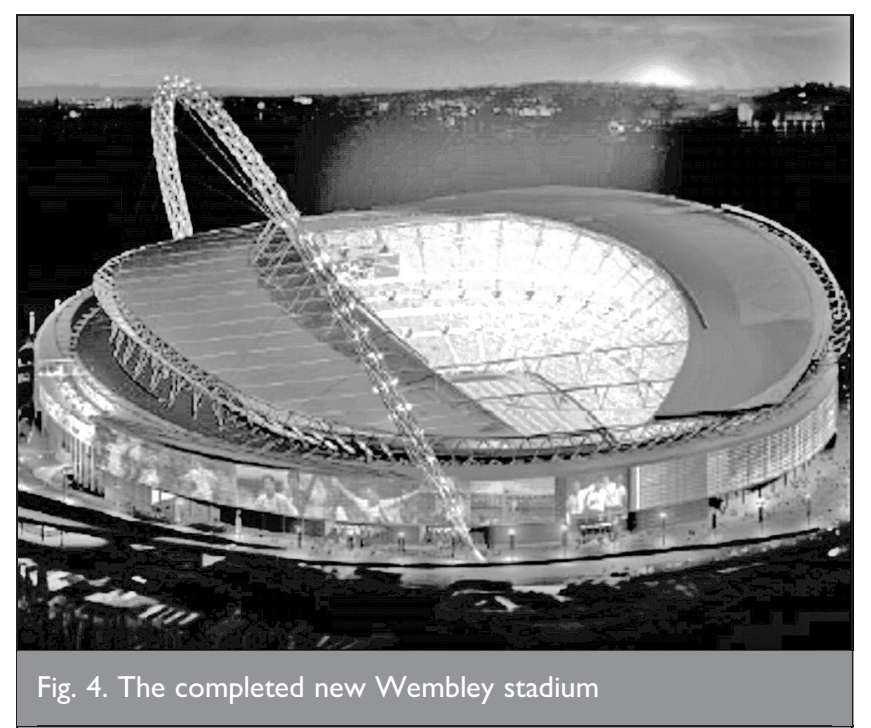

Some clubs choose to build iconic stadiums as a means of establishing differentiation and brand identity. The project management challenges of constructing iconic stadiums are well illustrated in the new Wembley stadium in London. The new state-of-the-art stadium was designed to have the largest roofcovered seating capacity in the world, capable of seating 90000 spectators. The original completion date for the project was May $2003,{ }^{5}$ however the stadium did not host its first sporting event until 24 March 2007, many months behind schedule. The cost of the new Wembley project soared from the original estimate of $£ 326.5$ million to $£ 792$ million, making it the most expensive stadium in the world. ${ }^{6}$ The increases in project duration and cost may be attributed to a number of differing factors. The Wembley design-and-build project was awarded based upon the lowest price agreed with Multiplex. This was contrary to current best practice that recommends contract award based on the level of innovation and creativity that meets the client's requirements. Client organisations with limited experience of large-scale iconic stadiums projects and design-and-build procurement soon realise that the cost of changes made after contract award is significant. Other factors that led to cost increases were associated with the poor relations between the primary contractor and sub-contractors; leading to the dismissal of the steelwork subcontractor.

The Wembley project suffered a catalogue of problems, from the death of a scaffold worker, to the strike of workers when 200 men were dismissed after a dispute about working hours and breaks. The project led to the resignation of the contractor's executive chairman and the near collapse of the company. Furthermore, the bad publicity and criticism of all parties did much to taint the image of the construction industry and undo any perceptions of its reformed status away from the bad reputation that the industry had long struggled to shed. Although the finished stadium is hailed by some as an icon worthy of the cost and delay (Fig. 4), questions linger about the challenges of delivering iconic stadiums. These issues are especially of interest to clubs that will seek to build iconic stadiums in future, and the principles equally apply to efforts towards the delivery of stadiums for the London 2012 Olympics. Therefore the next section discusses the project management challenges of delivering iconic stadiums based on a number of case studies and best practice review.

\section{PROJECT MANAGEMENT CHALLENGES OF DELIVERING ICONIC STADIUMS}

In investigating the project management challenges associated with iconic stadiums, a life-cycle framework was adopted. The various project management standards including: the Association for Project Management's body of knowledge, ${ }^{7}$ the Project Management Institute's body of knowledge ${ }^{8}$ and the British Standards for project management ${ }^{9}$ all divide the project life-cycle into various phases. The number and terminology may be different but the four core stages of initiation, planning, implementation and termination are easily recognised as generic. The case studies and subsequent interviews revealed that the implementation and terminating phases were generally smooth. The greatest difficulty was experienced at the initiation and planning stages. In cases such as the new Wembley stadium project where significant difficulties were experienced in the implementation phases, the source of problems could usually be traced to actions or decisions taken in the earlier phases. ${ }^{6}$ Smith ${ }^{10}$ explains that the greatest opportunity to make major decisions with minimal cost impact is at the early stages of the project. Fig. 5 illustrates this point.

Beyond the planning phase, the cost of change becomes higher. It was therefore not surprising when the interviews and case studies revealed that issues around initiation and planning stages featured prominently among the project management challenges of delivering iconic football stadiums. Specifically, the study revealed that client management, stakeholder expectation management, choice of procurement and design management; all of which are upfront activities had a big impact on the outcome of iconic projects. Therefore, rather than discussing the entire project management body of knowledge, the following section addresses the key issues that emerged at the early stages of the project.

\section{I. Client management}

Client management skills are increasingly being recognised as a prerequisite to successful project delivery. In fact the growth of project management as a profession has risen out of the need to provide an interface between the client and the rest of the project team. Control over and co-ordination between the building professions and the on-site production process was initially the central function of the project manager. Ball ${ }^{11}$ reports that the project manager may be an individual or company from any one of the building professions, a contractor,

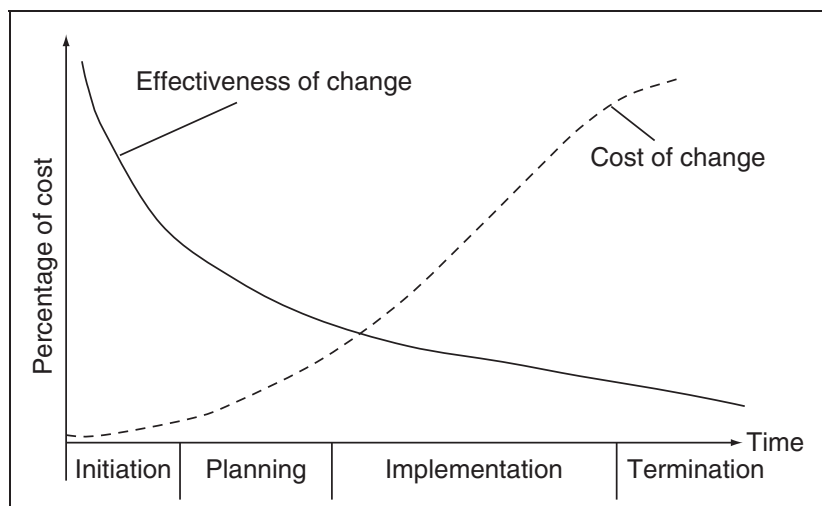

Fig. 5. Important decisions should be made early: adapted from Smith ${ }^{10}$ 
or a firm from outside the construction industry altogether. Nevertheless, the focus in the past has been on the project manager's ability to deal with the project participants. client management skills are, however, increasingly becoming a necessary part of project success.

Football clubs are usually run at a strategic level by the chairman and board of directors. It is this group of individuals who usually form the client or project promoter. They are highly experienced in the running of the football club as a sport and business, but they are often less knowledgeable about the delivery of large-scale construction projects. This is significant in view of the client typologies developed by Masterman and Gameson, ${ }^{12}$ which classify clients into 'primary' and 'secondary' experienced construction client organisations. Male (in Bower ${ }^{13}$ ) takes account of recent advances in procurement and the construction industry by categorising clients as 'knowledgeable regular procurers', 'less knowledgeable infrequent procurers' and 'ad hoc procuring' clients. As the procurement of iconic football stadiums is expected to be a one-off major undertaking, it is reasonable to classify football clubs as ad hoc clients. In this sense their comprehension of construction procedures is limited. A key project management challenge would therefore be to develop the right relationships that foster frank and timely communication regarding the client's requirements and expectations.

Stadiums are also evolving into multi-use facilities and as a result football clubs may enter into long-term collaborative arrangements with other organisations. For example, in the development of Liverpool Football Club's new Stanley Park stadium the local council is heavily involved and sees this project as an opportunity to regenerate the surrounding areas. These may be some of the factors that have contributed to increases in costs of up to $£ 150$ million; even before application for planning permission. ${ }^{14}$ Other organisations may include secondary investors and private developers. For example, Portsmouth has formed a joint venture with the private investment and development company Sellar Property Group and Everton has entered into a collaborative agreement with Knowsley Borough Council and the supermarket giant Tesco. Although these agreements benefit the club financially they increase the complexity associated with the management of the project 'client'. As a result the project management issues may involve dealing with secondary and tertiary clients.

\subsection{Stakeholder expectation management}

Closely linked to client management is the role of stakeholder expectation management. ${ }^{15}$ For iconic projects this is even more crucial. For example the management of the primary and secondary stakeholders for the Wembley project was vastly more complex and troublesome in comparison to the stakeholders associated with Sunderland's Stadium of Light ground. The stakeholder issues in the Wembley project may have been exacerbated by the mixture of public and private funding in comparison with the Sunderland stadium which was purely private. The public body stakeholders associated with Wembley stadium had very diverse requirements which were linked to the release of their funds. ${ }^{6}$

In the delivery of an iconic stadium, the stakeholders include: the 'client' (primary, secondary and tertiary) and the design team. The growth of premiership clubs has also resulted in various consumer groups, fan clubs, government regulatory bodies, major commercial sponsors and investors, etc. who all have a say; albeit to different degrees on the shape and eventual success of the project. Reconciling the expectations of these stakeholders is a significant project management challenge.

The first point of contact is usually the club project promoter who will have a rough idea of the club's strategic expectations. The application of techniques of value, requirements and risk management are very crucial at this stage to clarify these expectations and produce a clear brief as early as possible. The project's objectives and the balance between time, cost and quality also need to be clearly spelled out and the implications communicated. This will ensure that the vision and expectations are matched by the funding available and that minimal changes that could grossly affect the project are introduced later in the project life cycle.

The crucial role of stakeholder expectation management was previously implicit in earlier versions of APMs body of knowledge but the latest edition ${ }^{7}$ dedicates a new section exclusively to stakeholder management; thus emphasising this important project management challenge. In addition to the client and stakeholder issues, consideration of the choice of procurement route and design management presents another challenge at the formative stages of delivering iconic projects.

\subsection{Choice of procurement route and design management}

Turner ${ }^{16}$ and Masterman ${ }^{17}$ show that the choice of procurement route is a function of various factors relating to the project's priorities and the client's characteristics. In a previous article in this journal, Male et al. ${ }^{18}$ discussed how the roles of designers change with choice of procurement route. Therefore, the preferred procurement route will have an impact on the eventual cost of the project, the timing and nature of involvement of the project participants, motivation of participants, the potential for disputes and the design/iconicity of the stadium.

Rowlinson et al. ${ }^{19}$ argue that the separation of the design from the construction phase of a project allows the design team to work independently of pressure from the contractors. Lawson ${ }^{20}$ explains that this environment is needed for designers to engage in intensive intellectual activity that allows for creativity and innovation which are critical ingredients for iconic structures. Of course the counter argument presented by Bower ${ }^{13}$ is the loss of buildability advice and the potential for adversity and cost escalation associated with traditional procurement. In the past, traditional procurement has been the preferred option for clients wishing to deliver iconic structures but with little knowledge of the construction industry. ${ }^{21,22}$ This allows the architect and other designers to clarify the client's requirements and translate these into technical solutions. In this procurement route the architect usually acts as project manager. Some clients engage the services of a separate project manager to act as the client's gate-keeper, working closely with the design team before involving other project participants.

The procurement strategies used on a number of the major developments of football stadiums in the past 20 years shows a 
very distinct pattern; with design-and-build procurement as the preferred route.

(a) Wembley: design-and-build.

(b) Arsenal Emirates: design-and-build.

(c) Liverpool Stanley Park: design-and-build.

(d) Milton Keynes: design-and-build.

(e) Millennium (Cardiff): design-and-build.

(f) Coventry City Ricoh Arena: design-and-build.

(g) Stoke-on-Trent Britannia: design-and-build.

(h) City of Manchester: construction management.

The choice of design-and-build may be due to the risk-averse nature of these ad hoc clients. The perception seems to be that the design-and-build option allows complete risk transfer to the construction team who then deliver a finished product for a pre-agreed price. The design-and-build procurement option has been criticised for being cost rather than design quality driven. The choice of this option in the above projects could therefore have been due to the desire for a single point of contact and price certainty.

Turner $^{16}$ and Morledge et al. ${ }^{23}$ describe four variants of the design-and-build procurement route. In simple or small-scale projects in which only a superficial amount of change is likely to occur during the contract period, the contractor usually has in-house design capabilities and produces all detailed drawings in-house. Therefore, in this instance no independent professional advice is sought. In medium-sized projects the client may appoint consultants to produce the concept design. Contractors are then invited to complete and guarantee the detailed working design in competitive tenders. The contractors' design team undertakes the detailed design and the construction of the building. Hence, the role of independent professional advice is restricted to the conceptual stages of the project and the contractor undertakes all management functions.

A third variant is known as 'novation' in which the design team is employed in phases, directly by the client in the concept stages. The design team's appointment is then novated or suspended during the construction phase and the contractor establishes a direct appointment with the design team. In this case, the design professionals start with a 'traditional' relationship with the client, however as the project develops they are employed by the contractor rather than by the client directly. This situation reflects a radical re-alignment of occupational relationships. Furthermore, design professionals are normally employed to provide technical professional advice, whereas the design-and-build contractor assumes the management role.

In the fourth variant of the design-and-build form of procurement, the client employs consultants to provide a full audit capability independent of the contractor's design team. Design professionals are then employed in the supervision of the scheme, to oversee the technical matters of the detailed design. They may also be required to provide a full site presence. In this instance, the design professionals assume a limited role within the development process, that is, one of a technical supervisory nature; however, the overall management function is still retained by the contractor.

A variant of design-and-build in which the design professional may take on a significant design management role is the design-and-manage approach. In this case, the design manager (usually a design professional, i.e. an architect or engineering consultant) has full control of both design and construction phases of the project lifecycle. This procurement route reestablishes the design professional in the management role. It does not, however, appear to be a popular procurement option. Indeed, it is not mentioned in the Royal Institute of Chartered Surveyors (RICS) survey of building contracts in use survey of $2005 .^{24}$

Among the projects that chose the design-and-build option, not much consideration was given to the variants and how these would help the projects achieve iconic design.

Other procurement routes such as management contracting and construction management seem to be on the decline across the industry. The above discussion of the choice of procurement and design management suggests that for delivery of iconic structures emphasis should be placed on enabling the designers to explore their full potential to come up with distinct iconic designs. The traditional procurement route seems to be the most conducive for this objective. However, design and build has been used in the construction of new stadiums in England. Although design-and-build may not lend itself to design innovation and creativity, the variants may be investigated. With the increase in the use of private finance in the public sector, it seems likely that some football clubs will consider some form of private finance initiative approach. In that case, hybrid procurement options would have to be investigated.

\section{CONCLUSIONS}

Delivering an iconic stadium project is a challenging endeavour. As discussed in this paper the project management challenges are usually centred round the formative stages of the project lifecycle during project initiation and planning. Key issues that require specific attention from a project management perspective gravitate towards client management, stakeholder expectation management, design management and the choice of procurement route. These early stages of the project require skills and approaches that emphasise the soft aspects and people skills of good project management. On the other hand, the use of value, risk and requirements management would assist in clarifying the project so that the design brief accurately captures the client's requirements and vision. In terms of design, the use of prototyping and modelling should be exploited to give the client a good visual impression of what is being procured before getting to site.

Iconicity in premiership clubs should, however, not simply be about delivering a new stadium with unique design attributes. Iconic status should be achieved within the context of an overall strategic change initiative. For the clubs, iconicity should be perceived to encompass unique values and a shared vision that will eventually lead to brand identity. This is crucial given the diversity of revenue sources and the importance of the global image the club wants to attain. It therefore seems reasonable to conclude that iconic stadiums should be conceived and delivered alongside other strategic projects such as cultural change, and organisational/business reform. The internal processes should also therefore be aligned with the external business environment. These strategic issues should be clearly 
understood and communicated to all parties involved in the stadium delivery to ensure attainment of iconic status.

\section{REFERENCES}

1. Parkes R., Houlihan A., Ingles G. and Hawkins M. The Football Money League. Sports Business Group at Deloitte, Manchester, 2007.

2. SKLAIR L. Iconic architecture and capitalist globalization. City, 2006, 10, No. 1, 21-47.

3. Betsky A. Icons: Magnets of Meaning. Chronicle Books, San Francisco, CA, USA, 1997.

4. Porter M. E. Competitive Strategy: Techniques for Analyzing Industries and Competitors: with a New Introduction, revised edition. Free Press, New York, 1998.

5. BBC SPORT. New Wembley rolls out the red carpet 2007. Available from: http://news.bbc.co.uk/sport1/hi/football/ fa_cup/6668447.stm. Accessed 31/05/2007.

6. National Audit Office. The English National Stadium Project at Wembley. The Stationery Office, London, 2003. See http://www.nao.org.uk/publications/nao_reports02-03/ 0203699.pdf. Accessed 04/11/2008.

7. Association for Project Management. APM Body of Knowledge, 5th edition. APM, High Wycombe, 2006.

8. PMI, ed. A Guide to the Project Management Body of Knowledge (PMBOK ${ }^{\circledR}$ Guide) 3rd edn. Newton Square, 2004.

9. British Standards Institution. BS6079. Guide to Project Management. British Standards Institution, London, 1996.

10. Sмiтн N. J. Appraisal, Risk and Uncertainty. Thomas Telford, London, 2003.

11. BALL M. Rebuilding Construction: Economic Change and the British Construction Industry. Routledge, London, 1988.

12. Masterman J. W. E. and Gameson R. N. Client characteristics and needs in relation to their selection of building procurement systems. East meets west. Proceedings of CIB W92 Symposium, 1994, University of Hong Kong, Hong Kong, 1994, pp. 79-87.

13. BOWER D. Management of Procurement. Thomas Telford, London, 2003.

14. BBC SpORT. New Anfield stadium costs soar 2007. See http://news.bbc.co.uk/1/hi/england/merseyside/ 7063388.stm. Accessed 26/10/2007.

15. PHILIP R. Stakeholder Theory and Organisational Ethics. McGraw-Hill Education, London, 2003

16. TURNer A. Building Procurement, 2nd edn. Macmillan, London, 1997.

17. Masterman J. W. E. An Introduction to Building Procurement Systems, 2nd edn. Spon, London, 2002.

18. Male S., Bower D. and Aritua B. Design management: changing roles of the professions. Proceedings of the Institution of Civil Engineers - Management, Procurement and Law, 2007, 160, No. 2, 75-82.

19. Rowlinson S. and McDeRmott P. International Council for Building Research Studies and Documentation. Procurement Systems: a Guide to Best Practice in Construction. E. \& F. N. Spon, London, 1999.

20. Lawson B. How Designers Think: the Design Process Demystified. Architectural Press, Oxford, 1997.

21. ARITUA B. Design Management in the New Collaborative Procurement Systems. MSc thesis, University of Leeds, 2005.

22. Dalal A. A. The Changing Role of Architects and Contractors. MSc thesis; University of Leeds, 2005.

23. Morledge R., Smith A. and Kashiwagi D. Building Procurement. Blackwell, Oxford, 2006.

24. Royal Institution of Chartered SuRveyors (RICS). Contracts in Use: A Survey of Building Contracts in Use during 2004. RICS, London, 2005.

\section{What do you think?}

To comment on this paper, please email up to 500 words to the editor at journals@ice.org.uk

Proceedings journals rely entirely on contributions sent in by civil engineers and related professionals, academics and students. Papers should be 2000-5000 words long, with adequate illustrations and references. Please visit www.thomastelford.com/journals for author guidelines and further details. 